\title{
Relajo y humor carnavalesco como sátira política en Un mundo maravilloso (Estrada, 2006)
}

\section{Relajo and carnival humor as political satire in A Wonderful World (Estrada, 2006)}

\author{
Violeta Alarcón Zayas \\ Universidad Complutense de Madrid,España \\ violeala@ucm.es \\ https://orcid.org/0000-0002-1995-5769
}

\section{Resumen:}

En este estudio se indaga la potencialidad contestataria de lo grotesco carnavalesco (Bajtin, 1974) desde las figuras del "relajo" y el "pelado", dos conceptos fundamentales del imaginario cinematográfico mexicano. Para esto, se analiza la película del cineasta Luis Estrada Un mundo maravilloso (2006), que junto a La ley de Herodes (1999), El infierno (2010) y La dictadura perfecta (2014) pueden considerarse una tetralogía sobre la situación sociopolítica actual de México, comparten temáticas, perspectiva crítica y satírica para retratar la historia social y política reciente de México, denunciando las turbias relaciones entre la corrupción política, el crimen organizado, las grandes corporaciones económicas y los medios de comunicación. Se comprueba finalmente cómo mediante el humor grotesco mexicano, la ambivalencia de la risa, la parodia, y la inversión carnavalesca, se delatan los mecanismos de opresión en el establecimiento y mantenimiento de la desigualdad entre las clases sociales y la distribución de la riqueza.

\begin{abstract}
:
This study investigates the rebellious potentiality of the carnival grotesque (Bajtin, 1974) from the figures of "relajo" and "pelado", two fundamental concepts of the Mexican cinematographic imaginary. For this, the film by the filmmaker Luis Estrada $A$ wonderful world (2006), which together with Herod's Law (1999), Hell (2010) and The Perfect Dictatorship (2014) can be considered a tetralogy about the current sociopolitical situation in Mexico, share themes, a critical and satirical perspective to portray social history and recent politics in Mexico, denouncing the murky relationships between political corruption, organized crime, large economic corporations, and the media. It is finally verified how through grotesque Mexican humor, the ambivalence of laughter, parody, and carnival investment, the mechanisms of oppression in the establishment and maintenance of inequality between social classes are revealed and the distribution of wealth.
\end{abstract}

\section{Palabras clave:}

Humor, grotesco, cine mexicano, necropolítica, análisis discursivo.

\section{Keywords:}

Humor, grotesque, Mexican cinema, necropolitics, discursive analysis. 


\section{Introducción}

Un mundo maravilloso trata sobre los avatares de un vagabundo ebrio, Juan Pérez (Damián Alcázar), que buscando infructuosamente un lugar donde pasar una lluviosa y gélida noche por las calles de Ciudad de México accede sin ser visto a un despacho de un edificio de oficinas de la WFC. Escondiéndose de un empleado de limpieza, Pérez queda atrapado en la cornisa del edificio a una vertiginosa altura. Asustado, grita y orina sobre unos ejecutivos, logrando llamar su atención, quienes al verle al borde del abismo creen que intenta suicidarse. El suceso provoca que acudan en tropel la policía, los bomberos y la prensa, desencadenando una serie de malentendidos en base a unas declaraciones falsas ingeniadas por un reportero económico (Martín Altomaro), que trabaja en El Mercurio, un periódico de izquierdas, crítico con las políticas neoliberales del gobierno. El periodista convierte a Juan Pérez en un héroe del pueblo, haciendo creer que la intención de Juan era inmolarse para denunciar la situación de pobreza e injusticia social del país. Esto genera un movimiento social masivo de rechazo hacia el gobierno, y en particular contra el ministro de economía (Antonio Serrano), situación de la que intenta beneficiarse Pérez, para casarse con su novia Rosita (Cecilia Suárez).

La película se construye desde la perspectiva de personajes socialmente oprimidos, marginales y pícaros, a los que en México popularmente se les conoce como "pelados” y cuya actitud vital característica es el "relajo" (Portilla, 1984). Esta forma de picaresca, suele tratarse en la literatura y el cine desde el patetismo realista o el humor costumbrista, que separa y subraya las diferencias sociales. Por el contrario, en esta película el relajo de los pelados se enfoca desde la ironía y el humor negro macabro, por un lado, y el humor festivo y satírico del "relajo" coincidente con las características que Bajtin (1974) atribuye al grotesco carnavalesco o popular. Frente al patetismo asociado al fatalismo determinista, el humor relativiza la realidad que descarna y exhibe, abriendo la posibilidad de cambio:

El humor cancela el patetismo, que es una actitud de desesperación ante la acción. El patetismo lleva implícita la afirmación: "no hay nada que hacer"; quiere consagrar, como insuperable, un estado del mundo. El humor destruye 
esta consagración y devuelve su carácter transitorio a la situación que el patetismo quería hacer definitiva. (Portilla, 1984, p. 85)

Además, la comicidad grotesca acerca realidades dispares en lugar de separarlas, las humaniza en vez de objetualizarlas, señala situaciones y estructuras que incluyen al espectador, acortando las distancias con la alteridad que se establece desde la hegemonía respecto a las realidades sociales marginales.

\section{Metodología y marco teórico}

Desarrollaremos un análisis discursivo de secuencias significativas del film para profundizar en la capacidad subversiva práctica de lo grotesco, es decir, comprobar su funcionamiento efectivo social, ético y político, a partir de una estética desestabilizadora, y así mismo, cuándo y cómo esta función crítica queda suspendida, neutralizada o asumida por el discurso hegemónico. Las secuencias elegidas condensan desde el humor grotesco elementos identificativos de los mundos antitéticos (la oficialidad y el relajo) representados en el film, ambas sintetizan los principales argumentos críticos ofrecidos por la película.

Indagaremos en este cine que se sirve del grotesco para dar voz a quienes no se les permite tenerla, y procura una mirada que muestra desde otra perspectiva las realidades excluidas $\mathrm{y} / \mathrm{u}$ oprimidas, al relativizar mediante el horror y la amarga comicidad del grotesco las verdades naturalizadas, las relaciones de poder normativizadas.

En este análisis, aplicaremos el concepto de grotesco que Bajtin (1974) denomina "realismo grotesco" o "grotesco carnavalesco". Se trata de una estética, una cosmovisión y un humor herederos del carnaval medieval. Nos ubica en una perspectiva donde durante la festividad popular "las transgresiones contra la propiedad y las jerarquías sociales estaban permitidas y, por un breve espacio de tiempo, el mundo se volvía cabeza abajo" (Connelly, 2015, p. 51), donde el pícaro, el loco, el delincuente, la prostituta y el bufón toman la palabra, adquieren protagonismo, se igualan o incluso ocupan el lugar del rey. Un humor que se identifica con la risa universal, que aproxima a 
lo terrenal, donde se borran las diferencias sociales, se juega con lo sagrado y pone de relieve la arbitrariedad de los dogmas.

\subsection{Pobreza y desigualdad en México: realidad e imaginarios}

\subsubsection{Contexto político}

Estrada denuncia la pobreza extrema en una situación de corrupción política y capitalismo salvaje, cuestión de índole global, pero con las particularidades históricas y geopolíticas de México durante el gobierno de Vicente Fox (20002006), cuya presidencia supuso la primera alternancia política al PRI en setenta y un años. Este gobierno, pese a sus promesas y programas destinados a paliar el desempleo y la pobreza, no modificó las "asimetrías de poder" ni "las tendencias de reproducción de pobreza" (Hevia, 2009, pp. 68-69), provocando un gran descontento social, con levantamientos populares de gran repercusión, como los de San Salvador Atenco, iniciados en 2001 contra la construcción del aeropuerto que desterraba a los campesinos, o la movilización de maestros en Oaxaca (2006) por la subida salarial.

\subsubsection{La ambivalencia del relajo}

Debido en parte a las grandes diferencias y distancia social y económica existentes en México, y en general en Latinoamérica, la concepción de la pobreza, creada por las élites, se asienta en un imaginario determinista que justifica dicha situación naturalizándola y que forja la literatura intelectual de clase alta desde finales del siglo XIX, perdurando hasta nuestros días Bartra (2000); Monsiváis (2000). Este imaginario acrecienta y legitima la distancia entre ricos y pobres, genera una diferenciación conceptual donde se oponen la idealización abstracta de "pueblo", de los términos despectivos de trasfondo clasista y racista, de "gleba" y "plebe" como aquello fuera de la sociedad, se asienta la representación de los pobres en los estereotipos que encarnan la inmoralidad y la abyección:

Metáforas del vicio y la resignación, los pobres ornamentan las novelas del naturalismo como ángeles caídos: no intuyeron la decencia y la degradación los consumió, o ,-lo más frecuente-, nacieron viles y refrendaron el estigma en su abandono. Según el naturalismo, lo popular es sordidez, falta de control, olores insalvables, inmoralidad impuesta por los rasgos faciales y el color de 
la piel, animalización que es credo de la sobrevivencia. (Monsiváis, 2000, p. 15)

Este imaginario, que condena a los pobres como "vulgo irremediable", fue redefinido por la renovación cultural en los años 1940, haciendo surgir entre 1935 y 1950, la idea de lo popular con estereotipos consagrados fundamentalmente por el cine que "exalta las comunidades sin futuro, pero con un presente divertido y pleno de afectos humanos" hasta finales del siglo XX (Monsiváis, 2000, p. 24-25). En el marco de este pensamiento de la pobreza, determinista y moralizante, aparece el concepto del relajo asociado a lo popular.

La definición que ofrece el DRAE del relajo es: "desorden, falta de seriedad, barullo; holganza y laxitud en el cumplimiento de las normas”. El filósofo mexicano Jorge Portilla (1984) subraya que el relajo es un comportamiento, cuya significación es "suspender la seriedad. Es decir, suspender o aniquilar la adhesión del sujeto a un valor propuesto a su libertad” (1984, p. 18). El relajo incluye la comicidad, pero no se reduce a ella, ni se co-implican necesariamente, sobre todo se opone al valor establecido, pues la seriedad se asocia "a la virtud, a la sobriedad y a la racionalidad” (Sánchez, 2012, p. 38). El relajo es el distanciamiento y negación del compromiso que impone un tipo de conducta, cuyo valor es la seriedad de la norma o ley, que el relajo relativiza, invirtiéndola e incluso denunciándola.

Bartra relaciona directamente el relajo con el estereotipo del "pelado mexicano”, mito del que hay varias versiones, entre las que Bartra destaca el modelo "cantinflesco", figura más internacional del relajo, en el que confluyen la pereza, el nihilismo, el sarcasmo y la evasión y que se distingue del pícaro tradicional europeo en que no emplea el lenguaje para comunicarse sino para “escabullirse” (200o, p. 147). Este tipo de pelado además de ser el estereotipo de harapiento urbanita:

[...] es un simulacro lastimero del vínculo profundo y estructural que debe existir entre el despotismo del Estado y la corrupción del pueblo. [...] Se comprende que entre la corrupción del pueblo y la corrupción del gobierno hay una correspondencia: este pueblo tiene el gobierno que merece. $\mathrm{O}$ al revés: 
el gobierno autoritario y corrupto tiene un pueblo que le acomoda, el que el nacionalismo cantinflesco le ofrece como sujeto de la dominación. (Bartra, 2000, p. 150).

Bartra considera que este "aceitamiento de las relaciones sociales" señala metafóricamente el funcionamiento que legitima la corrupción del sistema político, cuya estructura es: "un laberinto de contradicciones, fintas ${ }^{1}, y$ albures $^{2}$ que permite que las más radicales demandas populares sean admitidas: inevitablemente se perderán en el dédalo de corredores, antesalas y oficinas, de manera que se disipará su sentido original” (Bartra, 2000, p. 148). Según este antropólogo, el relajo está implicado en este laberinto de gestos verbales evasivos, que originalmente surgen como forma de habla defensiva contra-hegemónica en los barrios más humildes y castigados. El relajo se concibe generalmente como el habitus (Bourdieu, 1998) propio de los parias, de la población más desfavorecida. El relajo se opone al apretamiento de las normas, supone librarse del corsé y violencia de las reglas, del oficialismo. En este sentido, el relajo, además de formas de subsistencia picarescas, implica un conjunto de conductas y códigos subversivos de resistencia al sistema moral y legal establecidos. Sin embargo, el relajo no es exclusivo del lumpen, los poderes fácticos lo adoptan también, fundamentalmente en la corrupción y extorsión. Es decir, el relajo, según quien lo ejerza, funciona como forma de supervivencia y de evadir la opresión, o como medio de ejercer el abuso y la dominación, y enriquecerse ilícitamente (Bartra, 2000, pp. 147-149). El relajo, como corrupción de las altas esferas políticas y sociales es representado en la película principalmente por el ministro, cuya forma de proceder se basa en todo tipo de sobornos, chantajes y mentiras, encarnando "ese gelatinoso aflojamiento de normas que permite una insubordinación limitada, que tolera un relajamiento dosificado de las reglas de comportamiento civil” (Bartra, 2000, p. 162).

1. Finta: Ademán o amago que se hace con intención de engañar a alguien. (DRAE).

2. Albur: En México y República Dominicana significa "Juego de palabras de doble sentido" (DRAE). Actualmente, estos juegos se basan fundamentalmente en alusiones sexuales. 


\subsection{Pelados, relajo y crítica social en el cine}

En el imaginario hegemónico cinematográfico los pelados aparecen como figuras claves de la comicidad, ejerciendo el relajo como catarsis o desfogue permitido por la oficialidad para que el pueblo no estalle bajo la presión de las leyes, la miseria y la marginalidad:

[...] la gran popularidad de Cantinflas se debe a que, con sus burlas, hace también una crítica de la injusticia social; [...] pero es una crítica conformista, que propone la huida y no la lucha, el escurrimiento y no la pelea. El mexicano se convierte en un maestro de las fintas y los albures. Él se vuelve un ser torcido, alambicado, evasivo e indirecto, dominado por el afán del circunloquio. (Bartra, 2000, p. 147)

Monsiváis (2006) señala que el relajo se consolida como característica de las clases marginales en obras clásicas de Rodríguez Ruelas Nosotros los pobres (1947) y Ustedes los ricos (1948) 3, así como en las películas de Tin Tan, y en especial El rey del barrio (Martínez Solares, 1950), que lograría la culminación triunfal del relajo, con un pelado como protagonista, un ladrón "robinhoodesco" que vive en constante engaño, disimulo y disidencia de las leyes y la autoridad. Los personajes del relajo en el cine clásico mexicano son siempre pobres, pertenecientes a grupos sociales excluidos, hostigados y oprimidos, que se rebelan contra su suerte: burlan la ley que les oprime; se desvían de la regla para sobrevivir; se evaden en las bromas, la fiesta o el alcohol y usan el humor negro para sobrellevar un presente precario e inestable y un futuro siempre incierto. Al igual que la comicidad puede utilizarse como válvula de escape catártica, para evitar que la presión subleve a la población contra el sistema, el relajo, por el contrario, como forma popular e irreverente frente al oficialismo de las normas, puede convertirse en un arma de reflexión y agitación contestatarias. La potencialidad subversiva y la pura diversión del juego del habla van unidos, pues el lenguaje figurativo y el ingenioso posibilitan expresarse contra situaciones represivas, así como para

3. Películas protagonizadas por Pedro Infante, y basadas en radionovelas, son un referente fundamental de la Época de Oro del cine mexicano y en particular de la representación de las clases más desfavo- recidas en el cine nacional desde el fatalismo melodramático. 
analizar "los conflictos e ironías" que producen las diferencias de clase, raza, género y orientación sexual (Rosaldo, 1989, p.215).

El modelo de cine crítico y de protesta mexicano, se distancian de la idealización de la pobreza y del humor paródico desde mediados del siglo pasado. Este cine se ubicó principalmente en el ámbito urbano de Ciudad de México ${ }^{4}$ y tuvo como modelo de referencia a Los olvidados (Buñuel, 1950), obra fuertemente influenciada por el neorrealismo italiano, que supuso por primera vez en el cine mexicano un intento desmitificador de la miseria y de sus efectos, basándose en casos reales de delincuencia juvenil, aunque con tintes de surrealismo. Los olvidados evita tratar la pobreza en términos maniqueístas como había establecido Nosotros los pobres (1948), pues la intención del aragonés era investigar cómo se comportan los seres humanos en situaciones de marginalidad y pobreza, es decir, retratar cómo sobreviven sin juzgar ni moralizar, apelando básicamente a la violencia de las imágenes (Gutiérrez, 2011, pp. 168-169). Continuando esta tendencia de denuncia desidealizadora desde los bajos fondos, cabe destacar Chin Chin el teporocho (Gabriel Retes, 1975), que narra en primera persona los avatares que conducen al acoholismo y la drogadicción a un joven del humilde barrio de Tepico.

Según Gutiérrez, a finales del siglo pasado se produjo un nuevo giro en el cine social, retomándose el interés por retratar y denunciar la pobreza, discriminación y violencia que sufre cotidianamente gran parte de la población del país, incluyendo temáticas antes no tratadas, especialmente desde el éxito internacional de Amores perros (González Iñarritu, 2000). En los últimos años la visión cinematográfica de lo marginal en México constituye "una crítica implícita al triunfalismo gubernamental sobre el combate a la pobreza, y un llamado de atención hacia el incremento de la violencia de género en la sociedad mexicana” (Gutiérrez, 2011, p. 179). En esta línea aparecen películas de temática de género, como Perfume de violetas (Sistach, 2000), film que retrata las situaciones de abandono, malos tratos y violaciones que sufren a

4. Ciudad de México pasó a simbolizar la propia crisis, por su alta densidad poblacional siendo el destino de casi medio millón de migrantes al año, especialmente a Netzahualcóyotl, la zona marginal o "ciudad perdida" mayor del país, la que a mediados de la década de los 50 del siglo pasado contaba con casi 800.000 habitantes (Gutiérrez, 2011, p. 169). 
diario niñas y adolescentes mexicanas en las grandes urbes, en un contexto de pobreza donde la vulnerabilidad femenina e infantil se agravan. El tratamiento de estas películas evita los eufemismos y la idealización, ahondando en realidades extremas, pero cotidianas y conocidas, aunque sigan siendo tabú. Además, en ambas se pone de evidencia la gran brecha que suponen las diferencias económicas y sociales en México, poniendo en entredicho la normatividad moral y la hipocresía de las clases acomodadas.

\subsection{Inversión carnavalesca de clase en el cine}

Un mundo maravilloso mezcla el análisis crítico con la inversión, distópicamente señala un futuro próximo indefinido en la Capital mexicana. El tratamiento de esta realidad está en deuda clara con el cine clásico de parodia y sátira social, representado por los hermanos Marx y Chaplin, a cuyas películas hay varios guiños, principalmente al vagabundo de Tiempos Modernos (Modern Times, Chaplin, 1936) donde los protagonistas de delirantes enredos, son desheredados, pillos y pícaros entrañables, que, a través de todo tipo de argucias, burlando la ley y la autoridad, sobreviven y tratan de salir de su pobreza y marginalidad.

Abundan los ejemplos fílmicos que se relacionan argumentalmente con esta película, si nos centramos en el cine, (a menudo inspirándose en la literatura) encontramos coincidencias en varias películas internacionales que juegan con los choques culturales que se dan al transitar la pirámide social de un extremo al otro, en el contexto del capitalismo. Así pueden mencionarse ejemplos como Al servicio de las damas (My man Godfrey, de La Cava, 1936), El gran dictador (The great dictator, Chaplin, 1940), My Fair lady (Cukor, 1964), Entre pillos anda el juego (Trading places, Landis, 1983) o iQué asco de vida! (Life stinks, Brooks, 1991). No obstante, una de las películas que más paralelismos presenta con la de Estrada, es Juan Nadie (Meet John Doe, Capra, 1941) aunque esta carece de la perspectiva paródica. En este film, al igual que en Un mundo maravilloso, el protagonista es un vagabundo utilizado fraudulentamente por los medios de comunicación, atribuyéndole un intento de suicidio que supuestamente habría cometido para denunciar la injusticia política y social en la distribución de riqueza y las asimétricas 
relaciones de poder. John Doe (Gary Cooper) se enamora de la periodista Ann Mitchell (Barbara Stanwyck). Ann es quien idea todo el engaño convirtiendo a John en un héroe y referente social revolucionario, mediante los discursos que ella le escribe a partir del diario de su padre con mensajes de solidaridad y apoyo mutuo para la transformación social desde la revolución pacífica del pueblo. No obstante, en este proceso se enamora de ella y de sus ideales, convirtiéndose en John Doe, el personaje que ella soñó. Por esto, dispuesto a sacrificarse para divulgar sus ideas, y renazcan la solidaridad y el apoyo mutuo entre la población, no se deja sobornar por los poderes a los que incomoda su mensaje y la repercusión social de su discurso. Por el contrario, Juan Pérez, aunque también utilizado por la prensa crítica con un gobierno que se jacta y vanagloria de haber eliminado la pobreza a fuerza de ignorarla, no tiene otro interés que salir de pobre para casarse, y no duda en aceptar sobornos o chantajear al ministro para recibir lo que quiere. John Doe es un héroe, altruista, que se sacrifica por unos ideales sociales, por su parte, Juan Pérez es un pelado, anti-heroico, más cercano a la caricatura que al ideal, a quien mueve su egoísmo individualista que provoca el entramado político, económico y social. En ambas películas, como en toda la tetralogía de Estrada, el comportamiento y reacción de los gobiernos y corporaciones económicas es el de la hipocresía, corrupción, amenaza y represión, que en el film de Capra se denuncia desde el emotivismo dramático y cierto tono esperanzador, mientras que la película de Estrada desenmascara el aparato del poder mediante un tremendismo ácido, una carcajada irónica y brutal que muestra una realidad implacable e injusta.

En el cine mexicano esta idea de intercambiar a un pobre por un rico, aparece especialmente en el género cómico que encumbra la figura hegemónica del pelado. Estrada hace guiños continuos al Cine de Oro mexicano y en particular a las películas de Tin Tan, tales como El Vagabundo (González \& Martínez Solares, 1953) o Vagabundo y Millonario (Morayta, 1958), donde los protagonistas marginales, alcohólicos, holgazanes y albureros, encuentran el amor tras una serie de enredos y casualidades, así como logran ascender a una mejor situación social. Estas películas ofrecen personajes picarescos, marginales y bufonescos, donde el héroe, que es un vagabundo, deja de serlo 
al insertarse en el cronotopo del género familiar que el cine hereda de la novela:

El héroe principal es, al principio, un hombre desamparado, sin familia, pobre; vagabundea por un mundo extraño entre gente extraña; sólo le suceden desgracias o éxitos casuales; se encuentra con personas casuales que resultan ser por razones que no entiende al principio, enemigos o bienhechores suyos (posteriormente todo se aclara por línea familiar). (Bajtin, 1974, p. 383)

Estas películas se resuelven felizmente gracias al núcleo de seguridad filial. Los desheredados expulsados por la sociedad, a través del reconocimiento de su estirpe, olvidada o ignorada, se reinsertan en la normalidad establecida, resolviéndose sus problemas económicos y amorosos simultáneamente. Un mundo maravilloso desarrolla este tipo de argumento, pero mediante la sátira festiva e irónica del humor grotesco, cambia la comicidad compasiva e inocua del pelado tradicional, por una crítica mordaz, macabra y subversiva, que carece del desenlace complaciente que caracteriza al discurso hegemónico del cine comercial.

\section{3. Érase una vez... México sin pobres}

La película comienza parodiando un recurso narrativo clásico. Como si de un cuento de hadas se tratase, el título de la película aparece escrito en un libro de tapa gruesa, recurso que sitúa el discurso en una ficción muy concreta, y que sin esfuerzo puede remitir al comienzo del clásico Nosotros los pobres, de la que hay múltiples citas y alusiones explícitas, en toda la película de Estrada. En Nosotros los pobres (F1), el libro lo encuentran dos niños harapientos en un basurero, y sirve como recurso más estético que narrativo, para introducir los créditos de la película. Al encontrarse en la basura, sucio y desvencijado, se supone fuera de la oficialidad, un relato desechado por la sociedad, como sus propios personajes, y remite a una enunciación ubicada desde el relato autobiográfico de los pobres, lo cual se subraya en el uso del "nosotros" en el título. Por su parte, aunque la película también se sitúa en clara complicidad con las personas en situación de pobreza y marginalidad, en Un mundo maravilloso $(\mathrm{F} 2)$ el relato está construido en tercera persona, y el libro aparece 
como dispositivo de narración omnisciente, desde el uso de la ironía, tanto en el desarrollo de la historia como en el desenlace, por ejemplo, desdiciendo o anticipando en la narración escrita en el libro lo que los personajes creen o esperan a lo largo de la película. Pero volviendo a lo que sugiere el comienzo meta-narrativo, tanto el libro como el término "mundo maravilloso" evocan un relato de ficción, ¿quizás una utopía? Efectivamente, esta idea se refuerza al leer en la primera hoja del libro la fórmula canónica de los cuentos tradicionales de fantasía: "Érase una vez" que coloca al espectador en un relato fantástico infantil, sin una ubicación espacio-temporal determinada, señalando que se desarrolla en "un futuro no muy lejano". Se observa que se trata de una parodia que compara el discurso hegemónico 5 con un cuento infantil de fantasía. La enunciación parodia aquí el relato que la oficialidad cuenta al pueblo para que éste duerma (y sueñe) tranquilo, desde el humor que delata y desnuda las falsas apariencias.

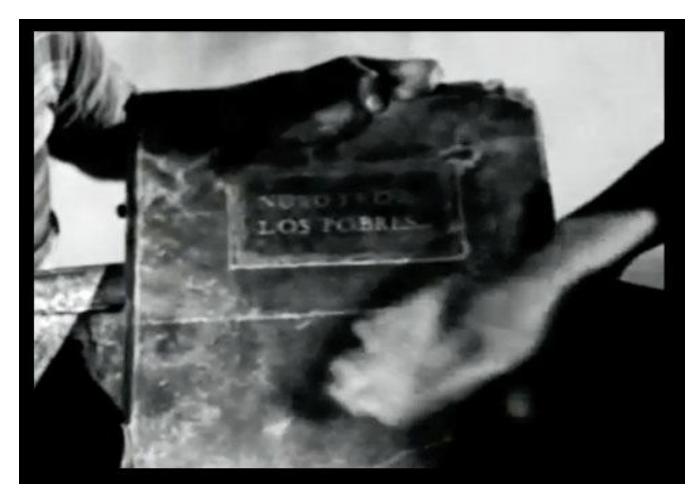

F1. Nosotros los pobres. Rodríguez

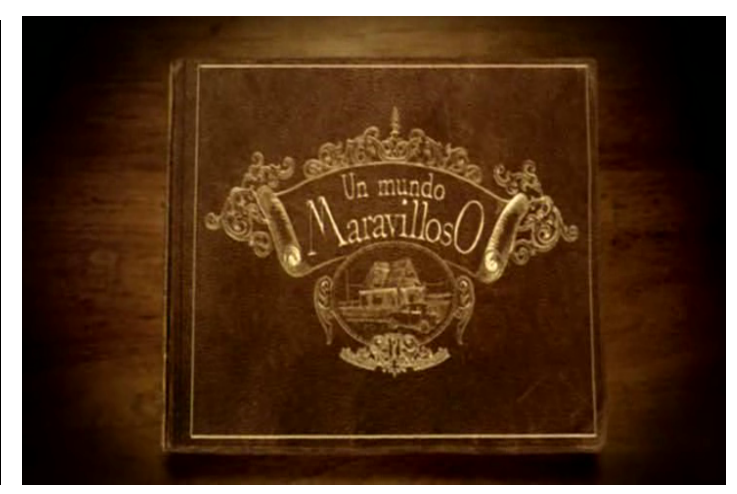

F2. Un Mundo maravilloso. Estrada

A continuación, asistimos al comienzo del relato, en un encadenado entre la ilustración del libro y la fachada real del Castillo de Chapultepec (F3). Se trata de un monumento emblemático ubicado en el corazón del bosque de Chapultepec, en Ciudad de México ${ }^{6}$. Este castillo, Museo Nacional de Historia

5. El discurso del poder en México se refleja y refuerza en la mayor parte del cine nacional, que sigue regido por diferentes tipos de censura (directa o indirecta). Esta censura cinematográfica, denunciada por muchos intelectuales y cineastas de izquierdas, (incluido Estrada): "sigue promoviendo un país idílico en el que no hay lugar para la corrupción, los políticos ineptos o las desigualdades sociales.” (Pfleger \& Schlickers, 2012, p. 45)

6. El Castillo, ubicado en un cerro sagrado mexica, se construyó como casa de verano del virrey de Gálvez, también fue hogar del emperador Maximiliano I de México, de Porfirio Díaz y residencia presidencial durante la República (1911 y 1935). Pero seguramente lo que lo hace más emblemático es lo acaecido cuando era sede del Colegio Militar durante la Batalla de Chapultepec el 13 de septiembre de 1847. La leyenda oficial, (muy discutida y actualmente 
desde 1939, ha sido escenario de representativos episodios de la historia nacional, por lo que condensa connotaciones diversas pero alusivas todas a la oficialidad. El relato funde dos significados principales, por un lado, el festejo en el castillo es un cronotopo idílico asociado al amor y la felicidad en los cuentos de hadas, pero este castillo, uniendo esta idea a evocaciones pretéritas a la monarquía colonial, apareciendo una corona en la primera página del libro. Por otro lado, juega su significado simbólico de defensa y creación del sentido actual de la patria mexicana desde el Porfiriato, así como del continuismo político del conservadurismo clasista y racista, lo cual se enfatiza en una secuencia en la que el ministro de economía llama "abuelo" a un retrato de Porfirio.

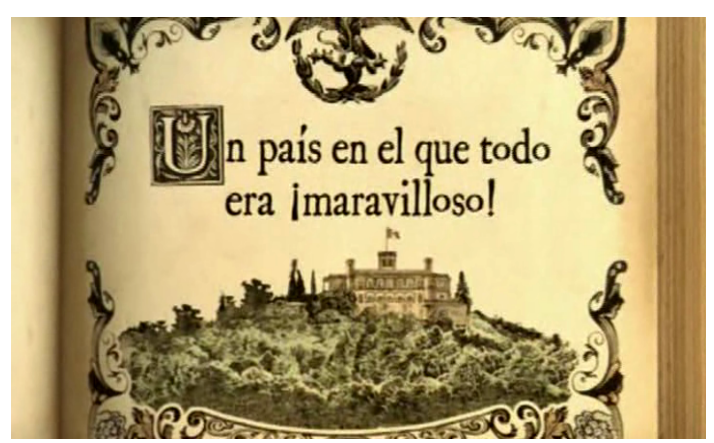

F3. Un Mundo maravilloso. Estrada.

En este lugar tan saturado de significados, se celebra un congreso internacional contra la pobreza, oficiado por el Banco Mundial. El ministro de economía mexicano, un hombre blanco, de mediana edad, ataviado con traje y pajarita, pronuncia un discurso en un inglés fluido, aunque con acento mexicano, sobre la situación del país. El público, en su mayoría de tez blanca y rasgos occidentales, escucha ensimismado e inexpresivo el discurso, desde la seriedad que caracteriza a la oficialidad (F4). El ministro afirma que México fue un país caracterizado por la "desigualdad social”, pero que gracias a la

desmentida con datos), dice que allí ocurrió el Martirio heroico de los Niños Héroes de Chapultepec, según el cual murieron por defender el castillo y la bandera frente a los soldados estadounidenses. Según esta versión, que todo mexicano conoce, uno de estos niños-cadetes, Juan Escutia, del que se duda su existencia, se envolvió en la bandera y se arrojó por la ventana para evitar que fuera mancillada. Esta leyenda supone la exaltación del orgullo nacional y el culmen del heroísmo patriota, lo cual también se puede relacionar con la falsa heroicidad que se le atribuye a Juan Pérez durante la película simbolizando la lucha de los desposeídos. Fuente: INAH https://www.inah.gob.mx/red-de-museos/295-museo-nacional-de-historiacastillo-de-chapultepec 
"guerra contra el hambre", llevada a cabo con la ayuda del "libre mercado" capitalista, "la globalización" y la colaboración de sus socios, a los que alude implícitamente, sobreentendiéndose que hace referencia a grandes corporaciones económicas internacionales y a países ricos, especialmente a Canadá y Estados Unidos, que aparece enguyendo a México (excluyendo Suramérica) en el logo a la izquierda del ministro (F4).

Dado que el inicio anticipa que la trama se va a desarrollar en un futuro no muy lejano, el mundo maravilloso que pinta el ministro de economía, al observar que sus receptores afirman y aplauden satisfechos ante sus rotundas afirmaciones, el espectador puede esperar una película en la que se va a mostrar un mundo "sin pobres”.

Asistimos a una celebración del poder, donde las élites imperialistas hacen gala de su hipocresía, brindando entre altas velas y platos vacíos preparados para un gran banquete por el derrocamiento de la pobreza. Este festejo de las instituciones políticas, religiosas y de las corporaciones económicas, cumple un papel legitimador del orden establecido, al igual que las celebraciones oficiales medievales: “consagrar, sancionar y fortificar el régimen vigente" (Bajtin, 1974, p. 11). En los festejos del poder, la temporalidad se establece como un constante progreso positivo donde las crisis quedan relegadas al pasado, reforzando una visión idealizada del sistema presente. La fiesta oficial consagra "las reglas" que rigen el sistema: "jerarquías, valores, normas y tabúes religiosos, políticos y morales corrientes”. Así, la celebración oficial supone "el triunfo de la verdad prefabricada, victoriosa, dominante" bajo "la apariencia de una verdad eterna, inmutable y perentoria” (Bajtin, 1974, p. 11).

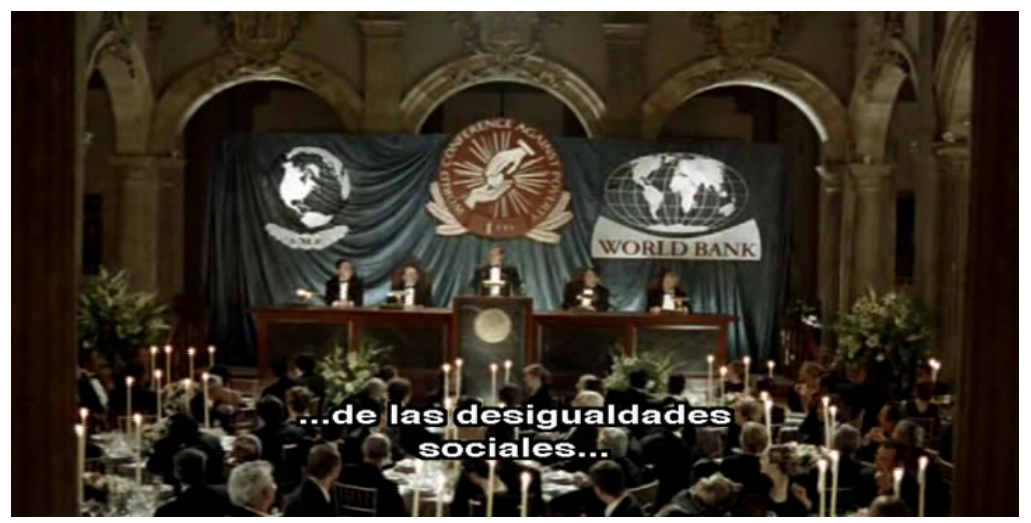

F.4. Un Mundo maravilloso. Estrada 
En los lugares de poder, alrededor del ministro, están sentados otros cuatro hombres, cumpliendo la representación canónica del poder actual: masculina, blanca, y trajeada. El logo central, -recurso paródico ya empleado en la controvertida La ley de Herodes y que se repetirá en toda la tetralogía-, explicita caricaturescamente el tipo de política e imaginario que subyace a esta celebración (F4). Consiste en dos manos que demarcan dos mundos contrapuestos: el de los ricos, que aparece en el extremo superior derecho del círculo, pues lo alto denota riqueza, virtud y poder (desde la metáfora locativa del cielo cristiano o el mundo de las ideas platónico), donde se subraya la idea del poder masculino con un puño de camisa en la muñeca, que por metonimia asociamos a un traje de varón. Esta mano ofrece una moneda a la otra mano con la muñeca desnuda, asociada al pobre que se dirige de abajo hacia arriba recibiendo la moneda, en un gesto que parece el de recoger una limosna. El logo parodia la ideología neoliberal y cómo disfraza sus políticas con los valores de la caridad cristiana, imaginario que divide el mundo en dos: ricos y pobres, donde aparentemente los países ricos velan y defienden los intereses de los países expoliados y empobrecidos.

Este discurso se cierra con la bendición solemne: "God bless you" que subraya el lugar meramente simbólico del cristianismo en el imaginario del poder capitalista, y a continuación, en un tono más relajado, que indica finalizar la etiqueta, añade en castellano: “como decimos en México: iSalud!”. Esta apelación a la divinidad, se manifiesta como sarcástica a lo largo del film, pues Dios solo aparece como fuerza benefactora invocada por los pobres, mientras las élites sólo la enarbolan durante las celebraciones oficiales, pero en la intimidad, el propio ministro se burla de la fe en Dios, que achaca a la ingenuidad e ignorancia de los pobres.

A continuación, la voz de Louis Armstrong cantando What a Wonderful World (1970) nos introduce con un travelling en el salón de una casa unifamiliar con jardín sobre la que llueve en la noche. Se trata de un hogar idealizado, donde una familia estereotípica, un matrimonio joven blanco, con dos hijos y un perro, disfrutan apaciblemente reunidos frente al fuego de la chimenea (F.5). La estética del mobiliario y vestuario evocan el cliché familiar estadounidense de la década de 1950, donde los roles de género están exageradamente 
marcados: el niño juega con su perro junto al padre que lee el periódico, la niña abraza sus peluches frente a la madre que borda, todo en el cronotopo de felicidad hogareña mainstream al calor de la chimenea que marca el centro de un cuadro armoniosamente simétrico.

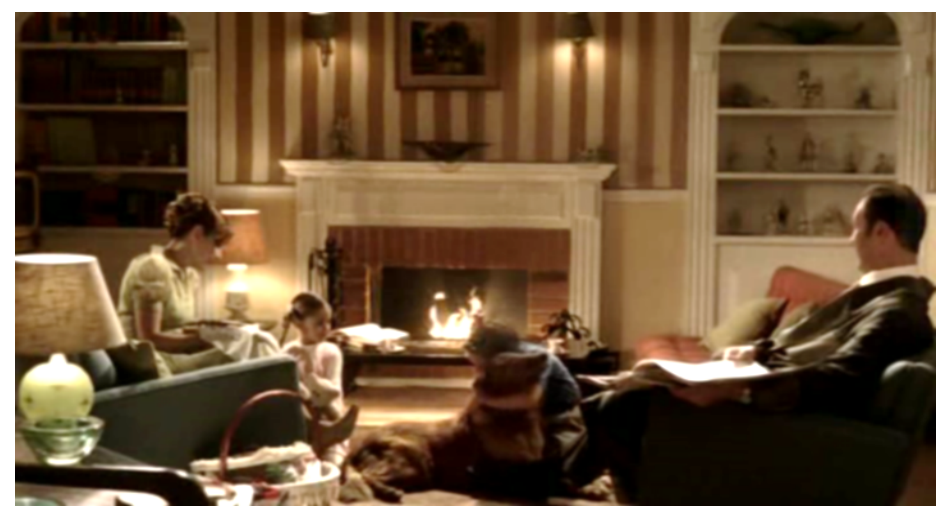

F5. Un mundo maravilloso. Estrada.

Esta es la "familia ejemplar”, según aparece en los créditos de la película: papá ejemplar (Rodrigo Murray) y mamá ejemplar (Cecilia Tijerina) que encajan con el ideal al que se refiere el ministro de economía, conforma el cronotopo del hogar feliz de clase media en el salón, lugar por excelencia de la convivencia hogareña: la casita unifamiliar en la zona residencial. La secuencia muestra un ambiente de equilibrio y comodidad, donde los niños juegan silenciosos, y los padres disfrutan del ocio que les corresponde por su género. El cuadro transmite sosiego, una alegría moderada, solemne, de imagen fija publicitaria: sin violencia, ni desorden, sin discusiones ni algarabía, sin pasión ni entusiasmo, con sonrisas suaves y gestos ensimismados. La familia ejemplar representa la inmutabilidad de la "verdad" oficial, como en el Mundo de las Ideas de Platón. En este paraíso capitalista, los clichés permanecen en un limbo, ubicados en cronotopos idílicos, plenos de felicidad hierática, salud, confort y belleza normativa y austera.

El espectador podría creer que estos son los protagonistas de la película, del mundo maravilloso sin pobres anunciado por el ministro, pero entonces aparece en escena Juan Pérez, (F6) un vagabundo de mediana edad, piel morena, bajito, desaliñado y borracho, que avanza bajo la lluvia hasta la ventana de la familia ejemplar para observar la felicidad que alberga un hogar del mundo maravilloso, a quienes envidia "hasta sus pantunflas". Pérez 
encarna esa realidad que se acababa de afirmar inexistente. Su presencia rompe con lo esperado, se produce el efecto sorpresa del que depende el humorismo, negando a quienes le han negado, y generando así el absurdo:

Para causar sorpresa el humorista tiene que tener sus dotes de originalidad la habilidad para romper las rutinas estereotipadas del pensamiento. (...) Tanto si pretenden comunicar un contenido social como si solamente desean entretener, deben proporcionar sacudidas mentales, producidas por la colisión de matrices incompatibles. Para cada situación o tema dado deben conjurar a un intruso apropiado o inapropiado que proporcione esa sacudida. (Koestler, 2002, p. 217)

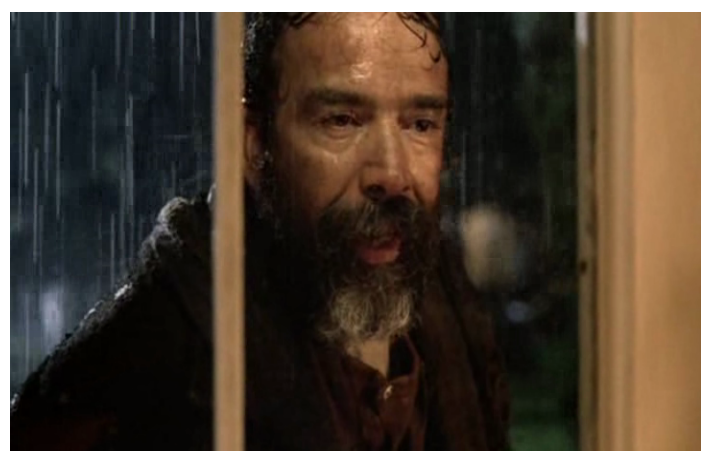

F6. Un mundo maravilloso. Estrada.

El contraste resulta grotesco, pues de la solemnidad del discurso de las élites y de la imagen hogareña idílica, nos damos de bruces sorpresivamente con el bufón esperpéntico, que produce la negación de la enunciación de la élite política: Pérez y sus compadres contradicen el discurso oficial que ubicaba la trama de la película en un futuro "maravilloso" sin pobres. Su aparición reubica al espectador ante una cruel y desigual realidad, un mundo de carestía, donde no hay trabajo, ni familia, ni casa, solo hambre, soledad e intemperie.

El espectador se da de bruces con el mundo de Pérez, un harapiento solitario, que vaga ingiriendo tequila bajo la intensa lluvia y el frío en busca de cobijo infructuosamente, expulsado violentamente primero de una marquesina de autobús y luego de una iglesia.

El protagonista se presenta desde una perspectiva humorística, sin dramatismo, pues no llora ante las calamidades que le acaecen y que ahoga en alcohol, solo se enfurruña y maldice, encarnando al pelado acostumbrado a este modo de vida. Simultáneamente, la letra de la banda sonora incide en la 
contradicción cómica al describir "un mundo maravilloso", pero también refuerza su actitud de relajo festivo. De hecho Pérez en su rol bufonesco pocas veces abandona el humor, incluso en los momentos dramáticos, pues "el humor nos libera de la miseria” (Sánchez, 2012, p. 60). Su carácter es pasional, alegre e improvisado. Los chistes, albures y juegos de palabras impregnan sus intervenciones. Pérez representa la inversión de la moral y de la seriedad que ésta implica, porque ser pobre no es sólo carecer de bienes materiales, significa además el reto a la moralidad oficial. Pérez no se ofende ante las burlas o los apodos despectivos, aquello que resulta ofensivo entre las clases altas, para los pelados puede llegar a significar motivo de orgullo, de hecho, él se presenta ufano como "El pinche Pérez", demostrando una inversión carnavalesca de los valores, frente a la oficialidad en que las élites se reconocen bajo títulos que subrayan su situación social, asociada al nivel académico: como "licenciado" o “doctor".

\section{Mejor un día de ricos, que toda una vida de pobres}

Cerca del final de la película, tras el fracaso reitereado de los pelados en sus intentos por escapar de la miseria, y el empeoramiento político social de los pobres, tras la nueva Ley que prohíbe la pobreza, persiguiendo la existencia de los propios pobres, el anciano Filemón afirma lúgubre: “Dios no existe”. Los protagonistas han evidenciado que, si Dios existiera, no se interesa por ellos, pues no se acerca a los callejones y alcantarillas donde se hacinan los marginados, de hecho, cuando han ido a buscarlo a "su casa" sus representantes les han golpeado y expulsado a puntapiés. Pero Pérez, contra la opinicón de su amigo, deduce que esto no significa la inexistencia de Dios ni del paraíso. Sonriendo afirma que no "sólo existe”, sino que él sabe "dónde vive”. Juan entiende que Dios existe, pero habita el Mundo de las Ideas, el mundo ejemplar de los hogares ejemplares.

Después de esta enigmática afirmación, se produce una elipsis y encontramos a Pérez con su hijo y su perro Lucifer en el salón de la familia ejemplar (F7). Los personajes muestran alegría y despreocupación, un completo relajo festivo en el que han adoptado con naturalidad los roles de la familia ejemplar. Pérez 
viste la bata del padre ejemplar y contempla la televisión con su hijo, que abraza al peluche de la niña ejemplar. Entonces, alguien llama al timbre y entran sus amigos pelados, parodiando mediante el disfraz, a una familia de clase media: Filemón lleva una bufanda elegante de cuadros, el Tamal luce un visón y el Azteca una gorra juvenil y todos cargan cajas de regalos navideños. Juan les pregunta por qué se han retrasado y el Tamal explica que han tenido un "conflicto" con los vecinos de "la nueva casa", añadiendo irónicamente: "pero hablando se entiende la gente y luego... Luego se quedaron bien quietecitos", tras lo que los vagabundos se miran entre sí con complicidad y ríen. A continuación, continúan una conversación insulsa, en la que Pérez interpreta su papel de buen anfitrión y les ofrece bebida, Filemón hace chistes y todo es chanza y euforia festivas.

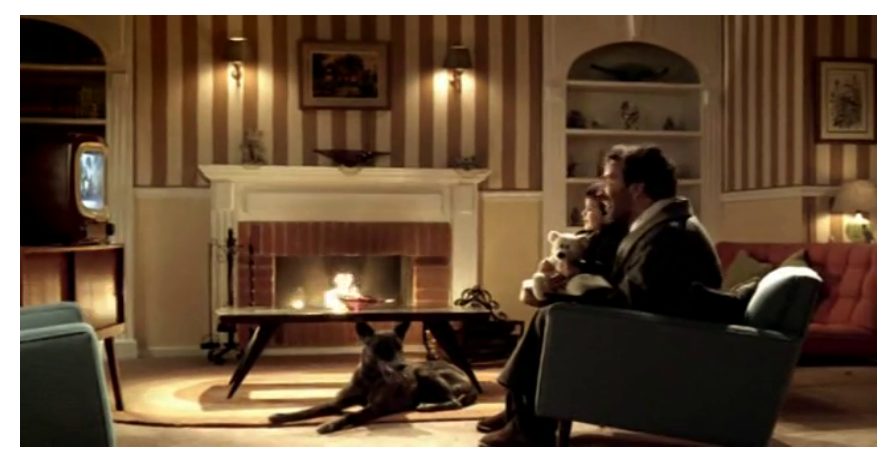

F7. Un mundo maravilloso. Estrada

Finalmente, irrumpe en el salón Rosita, vistiendo el mandil de la mujer ejemplar, cargando con un enorme pavo reluciente y convocándoles para cenar. Todos se sientan a la mesa que ella ha colmado de abundante comida, frente a la que los comensales brindan cada uno con su propia botella, riendo a carcajadas y haciendo gala de sus costumbres y habitus de pelados que han trasladado a un contexto de abundancia pantagruélica. Hasta aquí encontramos la alegría carnavalesca:

No es en consecuencia una reacción individual ante uno $\mathrm{u}$ otro hecho "singular" aislado. La risa carnavalesca es ante todo patrimonio del pueblo [...]; todos ríen, la risa es "general”; [...], el mundo entero parece cómico y es percibido y considerado en un aspecto jocoso, en su alegre relativismo; por último, esta risa es ambivalente: alegre y llena de alborozo, pero al mismo 
tiempo burlona y sarcástica, niega y afirma, amortaja y resucita a la vez. (Bajtin, 1974, p.13)

Esta fiesta se basa en el renacer tras la muerte, en la afirmación que invierte negando, que ríe a partir del llanto, que emerge a partir de lo que la elipsis oculta, desvelándose en la secuencia final. La película termina con esta peculiar cena, parodia del festejo hegemónico familiar, que Pérez inaugura con un brindis: "Ya se los dije: es mejor un día de ricos, que una vida de pobres" a lo que todos asienten, beben y la pareja se besa (F8). Entonces, en un travelling que se aleja de la mesa donde todos se disponen a degustar el banquete, la cámara se aleja atravesando la ventana hacia el exterior dejando
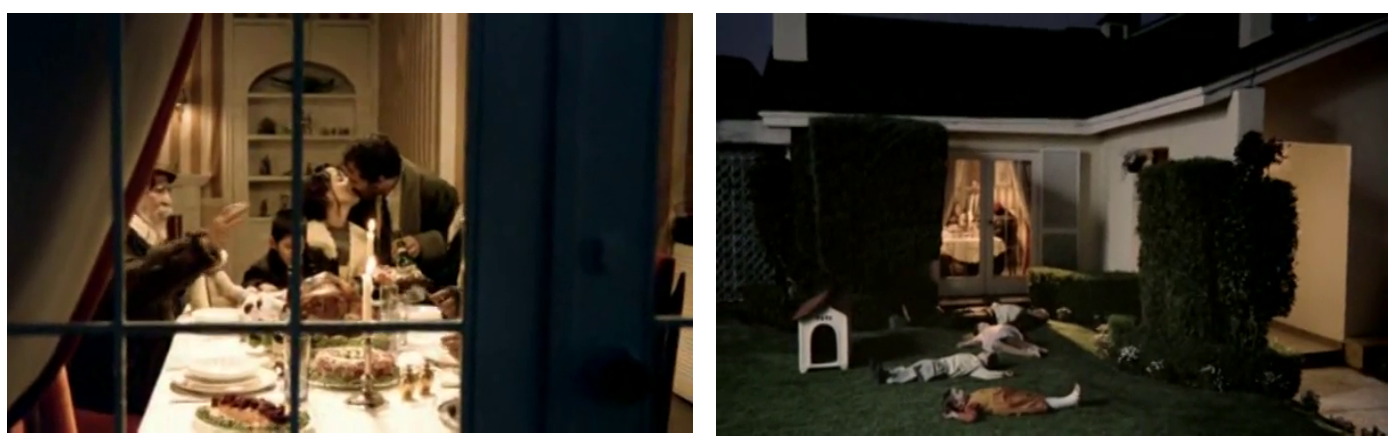

F8. Un mundo maravilloso. Estrada

ver la entrada de la casa y el jardín. Mientras emerge nuevamente la voz de Armstrong cantando What a Wonderful World el plano se sigue abriendo mientras aparecen uno a uno, los cadáveres de todos los miembros de la familia ejemplar, que yacen en fila sobre el césped frente a la puerta de la casa. $\mathrm{Al}$ expandirse el espacio de visión, se abre el de comprensión, dando un giro que torna la alegre celebración, en una situación de sorpresa incómoda que une muerte y vida, pero no como la muerte natural sigue al nacimiento en la celebración carnavalesca, sino que el humor macabro emerge congelando la risa suscitada en un primer momento. Aunque se podía sospechar el secuestro o asesinato de la familia ejemplar y de sus vecinos, no deja de producirse el choque traumático entre los cuerpos abandonados sin vida y el alegre festejo, lo cual se intensifica por el tono y letra de la canción. Esta secuencia funciona como reflejo esperpéntico del inicio del film, donde la celebración de las clases altas y medias se desarrollaban a costa de ignorar la muerte y miseria de los desposeídos. Se confirma esta inversión de los roles, que ha pasado por un 
crimen absurdo y cruel que recuerda la sátira de Viridiana (Buñuel, 1961). Lo traumático ahoga la risa macabra en una sonrisa irónica, porque surge de la unión de momentos fuertes contradictorios: el cronotopo idílico del festejo familiar y amistoso, en confrontación con un asesinato múltiple. La lógica que subyace a este crimen nihilista, es el reflejo invertido de la política de exterminio del sistema que encarna la ley del ministro de economía, un tipo de necropolítica basado en el genocidio de los pobres para acabar con la pobreza, justificaba desde un descarnado liberalismo, donde, eliminar lo improductivo supone proteger a la sociedad y su economía. Consecuentemente, los pobres al percibir a la sociedad como amenaza, la atacan ocupando el lugar que se les ha negado.

Esta nueva perspectiva cambia el sentido moral de la celebración, donde pasa a primar lo material: el bien (el paraíso) se concibe como puro placer físico, vaciado de todo contenido espiritual o moral. Las fiestas de los locos suponen dicha degradación: "Casi todos los ritos de las fiestas de los locos son degradaciones de los diferentes íconos y símbolos religiosos transferidos al plano material y corporal" (Bajtin, 1974, p. 63). El relajo encaja con este espíritu transgrediendo un valor, norma o ley, y en esta renuncia, se niega a esa misma sociedad, sus creencias y ritos, porque dicha sociedad a su vez oprime a quienes las infringen. La afirmación del disfrute de los vagabundos pasa por la negación de la vida de la familia ejemplar, asistimos a una lógica invertida:

[...] la lógica original de las cosas "al revés" y "contradictorias", de las permutaciones constantes de lo alto y lo bajo (la "rueda") del frente y el revés, y por las diversas formas de parodias, inversiones, degradaciones, profanaciones, coronamientos y derrocamientos bufonescos. (Bajtin, 1974, p. 13)

En esta inversión, pese a su crueldad, la enunciación mantiene la empatía hacia los protagonistas,-que han sufrido verdaderas vejaciones y desgracias-, desde el humor carnavalesco. Además, el tratamiento de la muerte de la familia ejemplar y sus vecinos no es dramático evitándose la violencia explícita. En sus intervenciones la familia ejemplar se presentó lejana, sus miembros planos, irreales e inocuos, y sus cadáveres se ven poco, la cámara 
no se detiene en ellos y en la distancia aparentan dormir plácidamente. No se adivina la causa de la muerte, no se advierten gestos de dolor ni síntomas de agresión, lo que evidencia que se rehúye culpabilizar a los protagonistas.

Por otra parte, el relajo refleja de forma aberrante el carpe diem capitalista e individualista ligado a un nihilismo maquiavélico y hedonista, en un mundo donde no hay posibilidad de salir ni pacífica ni legalmente de la pobreza, pero donde tampoco hay un proyecto social alternativo ni subversivo. El relajo transgrede y evidencia la injusticia, pero no la cambia. La única vía que queda para los habitantes de las calles, alcantarillas, chabolas y favelas, es la de escurrirse por el terreno aceitoso del relajo hasta hundirse en el fango, del delito y el crimen. Su vida es ya ilegal, nada les vincula con los valores establecidos, que en este caso los condenan al infierno en vida y a la muerte. Los pelados no pueden escapar del infierno al que les condena el sistema, idea que reitera Estrada en su crítica al necropoder y la narcocultura en el Infierno, donde hacerse narco es la última alternativa a la miseria. Por tanto, la decisión de Pérez, es radicalmente coherente con el relajo nihilista del capitalismo gore, pero desde la perspectiva del oprimido: ¿por qué seguir agonizando en las alcantarillas si podemos vivir (aunque sea un rato) en el paraíso? ¿Qué sentido tiene el futuro si irremediablemente nos aguardan el infierno y la muerte? Tras comprobarse que no pueden derrocar al ministro, rebajan sus expectativas y atacan una vivienda unifamiliar de clase media. "El relajo es, pues, la violencia y la revolución bajo su forma dócil y domesticada. Es, ciertamente, la revolución privada: una revolución que niega a las masas” (Bartra, 2000, p. 162). Este relajo resulta efectivamente destructivo y nada revolucionario. La acción de los pelados deja de ser esquiva para ser activamente agresiva: matar y expoliar para darse un festín. El crimen de los vagabundos daña a la sociedad, pero también es autodestructivo, pues supone una supresión del tiempo y de la libertad, ni siquiera se molestan en planificar el crimen y eliminar las pruebas porque el futuro no les interesa, se produce una total negación del futuro. La temporalidad se ciñe al presente más inmediato.

El no que el relajo opone a la realización del valor desemboca en él mismo. El relajo quiere, literalmente, una libertad para nada. Libertad para no elegir nada. Promueve el desorden para no tener que hacer nada en una acción 
prolongada y con sentido, tiene como fin la irresponsabilidad. (Portilla, 1984, p. 84)

El sujeto del relajo efectúa un movimiento profundamente irracional que consiste en suprimir todo futuro regulado, no hay más plan que el disfrute presente, y así el futuro resulta despojado de su poder de atracción. Cada instante del futuro inmediatamente próximo es vivido como una mera posibilidad de negación del presente (Portilla, 1984, p. 39). El relajo llega hasta las últimas consecuencias del nihilismo, no importa el castigo, la muerte, la cárcel o la persecución, solo queda rebañar desaforadamente el instante presente.

\section{Conclusiones}

El humor grotesco en Un mundo maravilloso juega con la tensión que provocan las relaciones de poder, denunciando un contexto sociopolítico concreto pero cuya crítica continúa vigente en el marco de corrupción y necropolítica neoliberal actuales. Bajo el esperpento se presiente una metáfora que provoca el abismo de lo traumático: este sistema de reparto desigual se basa en que unos vivan, coman, amen y disfruten, sobre los cadáveres abandonados de quienes mueren de hambre y miseria.

Se invierten los papeles, pero la estructura se mantiene, unos mueren para que otros celebren y disfruten. El sistema está montado de tal manera que unos pocos disfrutan de privilegios y seguridad absolutos en la cúspide social, a costa de una mayoría en situación de extrema pobreza junto a otra gran parte en situación de vulnerabilidad. Sociedad que no deja alternativa a los oprimidos, gobernados por la Ley de Herodes: "o te chingas o te jodes", moraleja satírica que se extrae, entre otras, de la tetralogía de Estrada.

Se demuestra que el relajo del pelado puede actuar como elemento subversivo cuando, en lugar de justificar la pobreza desde la caricatura amable del humor significativo, denuncia, desde la alegría grotesca del relajo, y la lobreguez del humor macabro, los dispositivos ideológicos y las estructuras de la necropolítica. Se desbarata el imaginario que señala a los pobres como un mal externo al sistema, y se presentan como algo intrínseco y fraguado en la propia 
sociedad, donde la situación de privilegio corrompe al individuo, al igual que puede corromperlo la miseria extrema, siendo la violencia causa y consecuencia de un sistema injusto de relaciones de poder.

\section{Referencias bibliográficas}

Bajtin (1974). La cultura popular en la Edad Media y El Renacimiento Madrid: Taurus.

Bartra, R. (2000). La jaula de la Melancolía. Identidad y metamorfosis del mexicano. Ciudad de México: Grijalbo.

Bourdieu, P. (1998). La dominación masculina. Madrid: Anagrama.

Connelly, F. S. (2015). Lo grotesco en el arte y la cultura occidentales. Madrid: A. Machado.

Connelly, F. S. (ed.) (2017). Grotesco y arte moderno. Madrid: A. Machado.

Cortina, A. (1997). Ciudadanos del mundo. Hacia una teoría de la ciudadanía, Madrid: Alianza.

Cortina, A. (2000). Aporofobia. El País, 7 de marzo, p. 14.

Estrada, L. (2006). Un mundo maravilloso. [Película]. Bandidos Films, Altavista Films, IMCINE.

Gutiérrez, O.S. (2011). La construcción del imaginario sobre la pobreza en el cine mexicano. Cultura y representaciones sociales. Revista UNAM. Vol 6, N.11.

Hevia de la Jara, F. (2009). De Progresa a Oportunidades: efectos y límites de la corriente cívica en el gobierno de Vicente Fox. Sociológica (México), 24(70), 43-81.

Koestler, A. (2002). "El humor como acto cognitivo" (El acto de creación: Libro I: El bufón). CIC Cuadernos de Información y Comunicación 7, pp. 317-327.

Monsiváis, C. (2000). Aires de familia. Barcelona: Anagrama.

Monsiváis, C. (2006). El nuevo darwinismo: 'El hombre desciende de la caricatura. Ciudad de México: Confabulario, suplemento cultural El Universal.

Pfleger, S. \& Schlickers, S. (2012). La ley de Herodes: tendencias del cine mexicano actual. La Colmena, (74), 41-48.

Portilla, J. (1984). La fenomenología del relajo y otros ensayos. México, Fondo de Cultura Económica. (2000)

Rosaldo, R. (1989). Culture and Truth: The remaking of Social Analysis, Boston: Beacon Press.

Sánchez, C. (2012). The Suspension of Seriousness. On the Phenomenology of Jorge Portilla. Albany: SUNY.

Valencia, S. (2010). Capitalismo gore. Barcelona: Melusina. 